\title{
New Culture Integration Process of Successful Educational Organizations in Merger
}

\author{
Achmad Supriyanto \\ Department of Educational Administration, \\ State University of Malang, Indonesia \\ a.supriyanto@um.ac.id
}

\author{
Burhanuddin \\ Department of Educational Administration, \\ State University of Malang, Indonesia \\ burhanuddin.fip@um.ac.id
}

\begin{abstract}
This study is aimed to identify the new integration process of an educational organization that has been successful in doing merger. The present study, approached with expost-facto, was conducted to organizations in higher education institutions. The data gathered are secondary data and analyzed using meta-analysis technique. The findings indicate that the integration of new cultures in the educational organization has been successfully done due to the capability of certain parties to synergize. the synergy is realized through several phases, such as clarifying the main point of culture, focusing on the new culture, actively managing the integration process of the new culture, realizing initiative actions, eliminating diparity, defining the new culture, building vision, contents, and new values, and measuring achievement and improving it.
\end{abstract}

Keywords: culture integration, organization, merger

\section{INTRODUCTION}

The study on organization merger is one of most concerned aspects in the field of management, particularly in management of organizational changes. The main rationale for this is that merger constitutes one of strategies of two organizations or more in dealing with each other's organizational problems ( $\mathrm{Yu}$, Engleman, \& Van De Ven, 2005), with which they are expected to grow stronger than ever. A number of definitions of merger have been proposed, among others, as a combination of two organizations into one (Chambers \& Lacey, 1994), a combination of two organizations or more in the attempt to creating a larger and greater organization than before, or to a new, better contained shape (Gitman, 1991), and such combination includes not only merger but also collaboration of programs and infrastructures (NPHE, 2001).

Bradt (2015) posits that the fundamental premise of any merger is that the merging entities will be more valuable together than they are separately. The fundamental premise of merger is the unification of entities that are better valued together than when separated. It denotes that the unification of an organization with another that synergize positively is a better form of it than administering the operational programs in separation. By this, organization merger becomes a very strategic alternative in organizational changes for now and later (Homburg \& Bucerius, 2006; Bligh, 2006).

Structurally, there are three categories of reasoning for an organization in doing merger, such as: (1) financial reasons, like in improving the synergy in financial achievement or economic scale (Price, 1999), taxes (Chambers \& Lacey, 1994), increasing shares value (Price, 1999), raising grants/ loans (Gitman, 1991); (2) strategic reasons, that is for increase in competitive gained revenues (Greengard, 1997), improvement of management skills (Gitman, 1991), and substituting an inefficient manager (Chambers \& Lacey, 1994); and (3) product diversification reasons (Chambers \& Lacey, 1994) which constitute penetration or domination of new markets, development of new products and services, improvement of new capabilities and sources (Price, 1999). These three categories often underlie merger between concording organizations.

Economy aspect, customarily, becomes the principal motivation to initiate merger, particularly in an educational institution (Pereira, 1999). Pocorobba (1999) suggests that several mergers in an educational institution may enable new institution to enhance the use of more expensive new technology products, as it has been exemplified by mergers done in UNISA/TSA/VUDEC. They require other new facilities and development of new programs as a consequence of implementing the merger.

Merger is an option to many organizations, be it educational, corporate, or banking organization, and others. In educational organizations, mergers can be found the stage of elementary until higher educational institutions. Mergers are also found in corporates, such as: (1) Chevron Pacific Indonesia (CPI); and (2) Chevron Indonesia Company (CICO) (Fajriah, 2016). Banking organizations usually also take the merger strategy, indicated by the merger scene before the bank integration of ASEAN 2020 (Mandala, 2015).

Some problems that commonly occur during merger that are indicated in the literature review indicate a number of types of problems inducing failure in doing merger, such as a careless management. This is related to issues about selecting the wrong partner, less appropriate internal policies, improper time for doing merger, less comprehensible plan, process, as well as the plan and process of management, and issues related to human resources.

One of key issues in merger associates with culture. Culture in this context comes from the new partner, who brings certainly a different culture (MacNeil, 2000; Veldsman, 1997). Clashes that occur between cultures may induce failure to receive the benefits of doing merger, and the other way around, should cultures from each organization unified, great benefits will follow. As regards with this point, plans can be better prepared to cause good meeting point between cultures thus the organizations can go on into the postmerger stage. 
O'Flaherty \& Conway (1990) signifies the danger of a partner unless purposes of doing merger are revealed. It may contribute to the failure in merger. Therefore, a group work is important to be created by the Ministry of Education as an attempt to prevent any failures in merger. The arrangement of rules and internal policies enable organizations to build positive conditions in supporting the success of doing merger (MacNeil, 2000). Such condition allows for building internal policies, mechanisms, and procedures. Further, based on the condition, higher education institutions are involved in developing the internal policies, mechanisms, and procedures of doing merger.

Mergers are also found to be discomforting because failures often happen when attempting to do mergers. Brad (2015) found that $83 \%$ of mergers have failed. Such failures are signified by mistaken leaders. Brad (2015) suggests that "the vast majority of leaders get something very wrong along the way". Cortina (2015) mentions that "despite the increasing popularity of mergers and acquisitions, it has been reported that more than two-thirds of large merger deals fail." Such failures happen because the leders ignores the importance of organizational culture integration. It is further emphasized that the cultural element is one of the key issues that may help explain the failure of many mergers (Cortina, 2015).

Earlier Bezuidenhout \& Hofmeyr (2000) have noted that in the beginning of doing merger financial aspect or strategies tend to reason out the merger, yet in the final development, cultural aspect is far more considered to be the main reason. Such development reveals that any reasons underlying organization in doing merger should be seriously considered. As regards with the failure in post merger (Moressi \& Pezzi, 2014; Pfister, 2009; Epstein, 2005), does not automatically cause the process of merger to stop, yet the organization's strategy in doing merger should continue. Such situation and condition highlight the importance of study which is related to the metaanalysis of new culture integration process as a determinant in a successful organizational merger.

Several mergers that have been known successful are determined by: (1) the specific value that will be created from the merger; (2) fully integrate the two businesses; and (3) ensure cultural compatibility (Brad, 2015) that are simplified into the variable of organizational cultures (Riad, 2005; Engleman \& Van de Ven, 2005). Based on the aforementioned description, a meta-analysis of new culture integration process of a successful ogranization in merger is highly necessary. The findings of this study can later become theroretical and practical bases for organizations to initiate merger.

\section{METHODS}

The method of this study covers design, data and its collection technique, as well as data analysis. The design of this study is based on its aim, which uses expost facto research. This study reveals a phenomenon which has happened in the real context that is obtained from study findings by experts. This study is conducted to the study findings concerning on organizational merger. Yet, this study is a separate stydy, for it is included in studies with observational retrospective, that is a meta-analysis study. The present investigation uses secondary data as the data and information obtained from previous relevant study findings (new culture integration process of a successful organization in merger). The findings from this study are documented in the form of article, published or not, in the relevant theme.

The criteria of selecting and collecting data from research articles that are included in the metaanalysis include the following points. The form should be: (1) all study findings analyzed are published and unpublished article that are found in scientific journals, proceeding, text book and/ or reference books, and also unpublished research reports; (2) the data are obtained through online and direct search to libraries in higher education institutions for relevant study findings (3) the search is done by the data collector; (4) the evaluation categories for the data include, design, conduct, and analysis; (5) classifying and coding the fields of study; and (6) abstraction or crystallization or quantitative and qualitative data of each study findings.

Data analysis technique used the combined meta-analysis model. This model is combining the meta-analysis of quantitative and qualitative data (meta-analysis dan systematic reviews). Meta-analysis is a systematic and objective analysis technique in combining data from multiple studies or reviews, which is predicted with the statistical analysis of quantitative study findings. Systematic reviews is also done to qualitative study findings. Such model is illustrated in Figure 1. Figure 1 describes that the data analysis in this study uses combined meta-analysis, that is the combination of meta-analysis and systematic reviews. It is based on the collected study findings that are quantitative and qualitative in nature. The findings of the combined meta-analysis are further analyzed in order to define the final findings.

\section{RESULTS AND DISCUSSION}

Based on the integration of the two groups of study findings, it is identified that the culture integration process of organizations which have been successful in doing merger are indicated in several studies in education, such as a study by Budiprasetyo (2006) who found that "the integration through cultural understanding contribute to the process of organizing, denoted by the direct and indirect effect to the variables of management behavior, internationalization strategy, and management of knowledge". Another study by Handoko (2013) yields that "the integration of a strong organizational culture impacts positively towards the performance of teachers in Private Higher Education Institutions (PTS) in the merger, proven by the finding of cultural effect towards work satisfaction and organizational commitment". Further, a study conducted by Wan \& Peterson (2007), reveal three points to ponder in the process of merger and culture integration in educational institution, such as (1) reviews of institutional integration which happen in higher education institution start from the planning of integration, integration process of post-merger, and 
result of such integration; (2) difficulties experienced by institutions, one of which, is building an identity which cannot be unified when establishing a new institution, one simple example is the clash that happens when creating a new name of the new institution; and (3) the integration of higher institutions is evaluated by two main dimensions, namely administrative dimension (efficiency and effectiveness of managerial) and academic results dimension.

\section{COMBINED META-ANALYSIS}

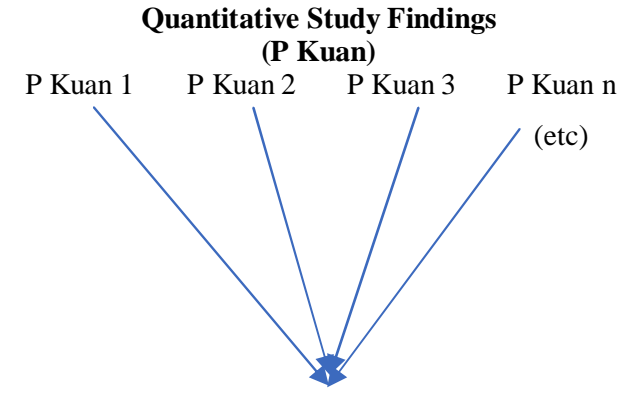

Combination of

Findings of Statistic

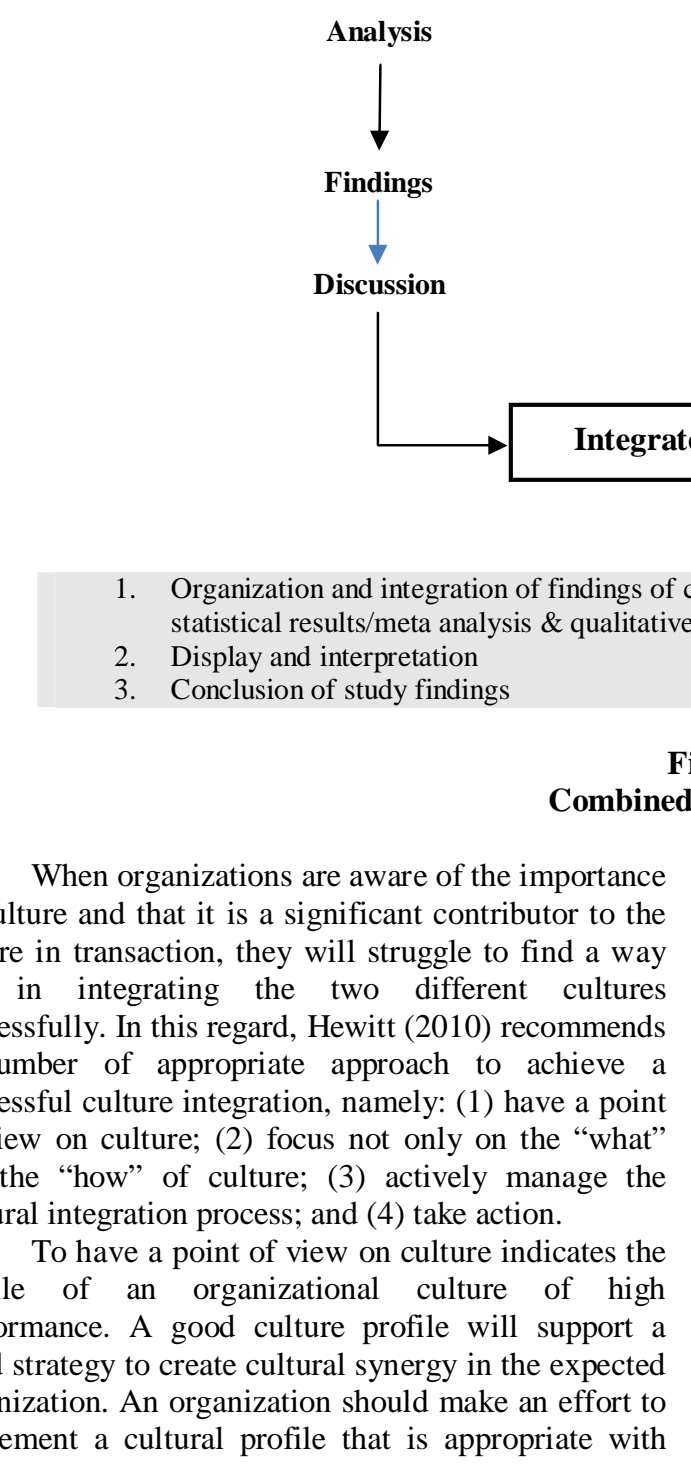

2. Display and interpretation

3. Conclusion of study findings

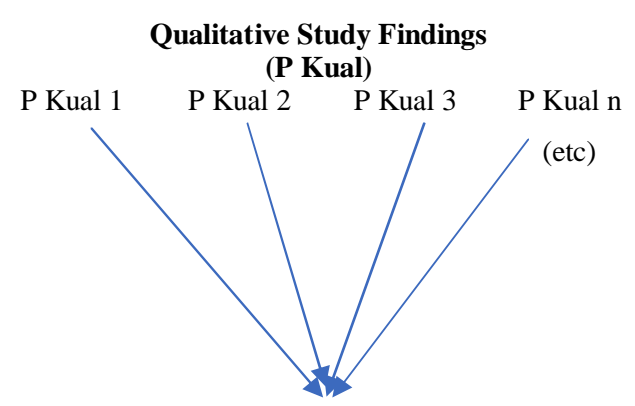

Systematic Reviews

(Critical review)

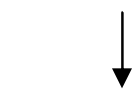

Findings

Discussion

Figure 1

combined meta-analysis (quantitative: combined/pooled statistical results/meta analysis \& qualitative: systematic reviews) 
The third aspect is to actively manage the cultural integration process. Steps that are important to take involve developing a holistic plan to manage the cultural integration process. The activity in this step includes stating a specific target to measure progress, ensure the harmony and relevance of working plot of culture with the business process, deliver how and why the experienced culture at the level of employee, and develop comprehensively a plan for changes and communication. A simulation of the plan can be initiated, which can make the management of cultural changes easier. Besides, such simulation can provide the leadership with a clear and tangible road map to follow and collect more leadership commitment and commitment in dealing with main causes of failures in cultural integration.

Finally, to take action refers to identifying organizational cultures and taking action to support the appropriacy of cultural integration with the organizational levels (sub organization), program, and individuals. It is important to ensure that the action is observable, coordinated, and motivated to express commitment in building an action-based culture. Such action highlights the characteristic of a shared culture between organizations with high performance in all kinds of strategy. An active cultural management is a key to successful integration thus lead to realization of the agreed purposes in doing organizational merger at the first place.

In line with Hewitt (2010), Steinmetz (2016) restate that in order to achieve the cultural integration, organizations should go through the seven following stages. They are leadership structure, cultural differences, diagnosis and prescriptions establish a communications council, define the new culture, vision, mission and values, cultural communications plan, and measurement and benchmarking. Leadership structure refers to the significance of a new, clear leadership structure and expressed like fashion. Such structure includes job descriptions and functions of every party undergoing merger. At this stage, the integration time, integration simulation between units, and agreement on topics and key issues should be clearly defined.

In addition, cultural differences, diagnosis and prescriptions indicate the need for a study on differences between organization, including the strength and weakness, and that it has to be visualized as an attempt to find the common points as a point in cultural integration. According to such condition, a consensus can be built up to reach agreement and minimize differences. Furthermore, to establish a communications council conditions leaders to be reliable organization navigators using good communication. Such talk should be transparent and honest in terms related to consolidation and chances of work severance, schedule, and future expectations. Optimize the empowerment of management professionals in communication to integrate the organizational cultures successfully.

The fifth is to define the new culture, and it is the key point in creating and defining a new culture. The use of software and social media collaboratively can be optimized to isolate main cultural components desired by the new culture. Unite all new, fresh, and attractive constituents for the future. Rewrite and socialize the culture manifestation and new statements, and celebrate how such points go together thus contribute to the future success. Next, the stage of vision, mission and values refer to activities that describe a new culture by defining the missions, longterm vision, and collective values for the new organization. Maximize the attempt to collect opinions and views, give feedback regularly, report progress to all levels of organization in order to reach the internal organization and field in a systemic and systematic manner.

In the stage of cultural communications plan, the senior leadership is responsible for communication plan, becomes the front and center of it, and own it as well. Communication is not a duty to delegate to members in the lower functional roles. There is a tactical communication plan that has to be systematic and in a chronological order within the set timeline for integration. Communicate regularly and to often use all innovation and new technological techniques, for examples, social media, online platforms, gamification, and web-based employment forum. Try out platform brands for cultural communication with a newly agreed key and icon logo.

Finally, the stage of measurement and benchmarking refers to the importance to undergo measurement and benchmarking to observe any achievement made. Reporting the progress and research benchmark to evaluate understanding and progress from time to time is necessary. This could be done by surveying all constituents every month with five simple questions and report the finings immediately via regular communication intensively to all levels in the organization.

\section{CONCLUSIONS AND SUGGESTIONS Conclusions}

New cultural integration in the educational organization has been successfully done due to the capability of certain parties to synergize. The synergy is not reached easily because the organizations have different background, therefore only commonly shared things can be integrated into one new thing. The stages they have to go through to reach the new cultural integration include: clarifying the main point of culture, focusing on the new culture, actively managing the integration process of the new culture, realizing initiative actions, eliminating diparity, defining the new culture, building vision, contents, and new values, and measuring achievement and improving it continuously.

\section{Suggestions}

For parties which are currently struggling with organizational merger should consider aspects contributing to the success of new cultural integration. Special attention to new integration aspects must be put in top priority because these are usually overridden thus may lead to failure. Some main steps to go through for the pertinent parties include finding a meeting point for the expected culture, optimizing the 
achievement process in a clear and utmost manner, and evaluating it periodically.

\section{REFERENCES}

[1] Bezuidenhout, A., \& Hofmeyr, G. 2000. Deft Touch Needed for Takeovers. Business Day, 23(2).

[2] Bligh, M.C. 2006. Surviving Post-merger 'Culture Clash': Can Cultural Leadership Lessen the Casualties. Leadership, 2, 395.

[3] Bradt, G. 2015. The Root Cause Of Every Merger's Success or Failure: Culture. Retrieved December 9, 2016, from http://www.forbes.com/sites/georgebradt/2015/06/29/th e-root-cause-of-every-mergers-success-or-failureculture/\#536dfed52173.

[4] Chambers, D. R., \& Lacey, N. J. 1994. Modern Corporate Finance: Theory and Practice. New York: HarperCollins.

[5] Cortina, C. 2015. The Role of Organizational Culture in Mergers and Acquisitions Management Consultant at Amg Consulting. Retrieved December 9, 2016, from https://www.linkedin.com/pulse/role-organizationalculture-mergers-acquisitions-cecilia-cortina.

[6] Epstein, M. J. 2005. The Determinants and Evaluation of Merger Success. Business Horizons, 48(1), 37-46.

[7] Fajriah, L. R. 2016. ESDM: Chevron Bukan PHK, Tapi Merger Perusahaan. Retrieved December 9, 2016, from http://ekbis.sindonews.com/read/1079992/34/esdmchevron-bukan-phk-tapi-merger-perusahaan145370970.

[8] Gitman, L. J. 1991. Principles of Managerial Finance. San Diego: Harper Collins.

[9] Greengard, S. 1997. You're Next: There is no Escaping Merger Mania. Workforce, 76, 52-62. Retrieved December 9, 2016, from http://education.pwv.gov.za.

[10] Hewitt, A. 2010. Culture Integration in M\&A. Retrieved December 9, 2016, from http://www.aon.com/a ttachments/thoughtleadership/M_A_Survey. pdf.

[11] Homburg, C., and Bucerius, M. 2006. Is Speed of Integration Really a Success Factor of Mergers and Acquisitions? An Analysis of the Role of Internal and External Relatedness. Strategic Management Journal, 27, $347-367$.

[12] Macneil, W. 2000. Pulling it all together. Community College Week, 13, 6-7.

[13] Mandala, A. 2016. Semarak Merger Jelang Integrasi Bank ASEAN 2020. Retrieved December 9, 2016, from http://indonesianindustry.com/semarak-merger-jelangintegra-si-bank-asean-2020/.

[14] Moressi, O., \& Pezzi, A. 2014. Cross-border Mergers and Acquisitions: Theory and Empirical Evidence. New York: Palgrave Macmillan.

[15] National Plan for Higher Education (NPHE). 2001. Plan Education. Pretoria: Ministry of Education.

[16] O'Flaherty, C., \& Conway, N. 1990. Merging Icebergs. Marketing Mix, 8, 24-26.

[17] Pereira, P. 1999. Winds of Change Blow Asmal's Agenda. Finance Week, 20 August, pp. 22.

[18] Pfister, J. 2009. Managing Organizational Culture for Effective Internal Control: From Practice to Theory. London: Springer Dordrecht Heidelberg.

[19] Pocorobba, J. S. 1999. Schools Team Up for Technology - American School and University, 72, 309311.
[20] Price, L. 1999. Helping People to Stay on Their Feet During Mergers and Acquisitions. People Dynamics, $17,38-42$.

[21] Riad, S. 2005. The Power of Organizational Culture as a Discursive Formation in Merger Integration. Sage Journal, Organiozational Studies, 26(10).

[22] Steinmetz, A. 2016. Seven Steps for Cultural Integration During A Merger or Acquisition. Retrieved December 9, 2016, from http://www.inwardconsulting.com/how-wethink/blog/seven-steps-for-cultural-integration-duringa-merger-or-acquisition.

[23] Veldsman $\mathrm{T}$ 1997. People Issues Essential for Corporate Marriages. Management Today, 27, pp. 31.

[24] Wan, Y. \& Peterson, M.W. 2007. A Case Study of a Merger in Chinese Higher Education: The Motives, Processes, and Outcomes. Retrieved December 9, 2016, from http://www.sciencedirect.com/science/article/pii/S0738 059306000800).

[25] Yu, J., Engleman, R. M., and Van De Ven, A. H. 2005. The Integration Journey: An Attention-Based View of the Merger and Acquisition Integration Process. Sage Publications, Organization Studies, 26(10), 15011528. 